\title{
PREGNANCY WITH A NORMAL LIVE FOETUS AND A PARTIAL MOLAR PLACENTA- AN EXTREMELY RARE CONDITION
}

\author{
KHANOM R ${ }^{1}$, KHATUN $K^{1}$, AKTER $\mathrm{S}^{2}$
}

\begin{abstract}
:
The incidence of a normal live foetus along with a partial molar placenta is extremely rare. Although triploidy is the most frequent association, a foetus with normal karyotype can survive in cases of partial molar pregnancy. A case is reported in the Department of Obstetrics \& Gynaecology, Dhaka Medical College Hospital, Dhaka that of partial molar placenta in which a live male baby was delivered at 34 weeks gestation by a 25 years old woman. At the 23rd week, ultrasonographic examination revealed a normal foetus with a huge, multicystic placenta. There were per vaginal bleeding up to the 34th gestational weeks. The patient underwent an emergency caesarean section and delivered a $1.6 \mathrm{~kg}$ male baby. The baby was admitted in $S C A B U$. The foetus was normal and no complication was there.
\end{abstract}

Key words: Live foetus with molar pregnancy, emergency caesarean section.

J Dhaka Med Coll. 2009; 18(1) : 82-84

\section{Introduction:}

Excluding cases of multiple conception with molar pregnancy and coexisting foetuses, partial molar pregnancy in which a live foetus is carried to term is very rare. Partial hydatidiform moles coexisting with fetal tissue or an anomalous foetus generally result from dispermy and have a triploid karyotype in the majority of cases $^{1,2}$. foetuses with triploidy cannot survive after birth because of multiple malformations and severe intrauterine fetal growth retardation. Several factors may affect the outcome of the foetus in cases of partial molar pregnancy, such as the karyotype of the foetus, the size of the abnormal molar placenta, the speed of molar degeneration, and the occurrence of foetal anaemia or other obstetric complications $^{3-6}$. Survival of a normal live foetus coexisting with the partial mole, unlike the classical complete mole and partial triploid mole, is extremely rare and may represent another disease ${ }^{6-8}$.

\section{Case report:}

A 25 years old female having $2^{\text {nd }}$ gravida, para $1+0$, with a history of last delivery 6 years back was admitted into BIRDEM Hospital at her 33 weeks 6 days of pregnancy with complaints of per vaginal bleeding, which started from 12 weeks of pregnancy but increased. Bleeding was continuing. At the beginning it was small in amount, but gradually increased. She was on regular antenatal checkup from $2^{\text {nd }}$ trimester onwards. During 23 weeks of gestation ultrasonogram showed a live foetus with partial mole. At 33 weeks 4 days of gestation, diabetes was detected. On general examination, she was found moderately anaemic but normotensive and her pulse was $76 /$ min. Abdominal examination showed that the uterus was about 36 weeks of pregnancy size, which was above than that of her gestational age, soft and non tender. Presentation was cephalic, Foetal heart rate was $140 / \mathrm{min} \&$ regular. Her haemoglobin conc. was $7.4 \mathrm{gm} \%$. Her blood group was 'B' negative and anti-D antibody was not found. $\alpha-\mathrm{hCG}$ showed gradually increasing level upto $25^{\text {th }}$ week and then decreased. As bleeding was continuing and increasing, she had to undergo an immediate lower uterine caesarian section (LUCS). From the histopathological study, it was revealed that the section showed many large

1. Assistant Professor, Department of Obstetrics \& Gynaecology, Dhaka Medical College, Dhaka.

2. Honorary Medical Officer, Department of Obstetrics \& Gynaecology, Dhaka Medical College Hospital, Dhaka Correspondence : Dr. Rashida Khanom 
chorionic villi, hydropic degeneration of the core, lined by proliferative tropoblastic cells which was a molar tissue i.e. Hydatidiform mole.

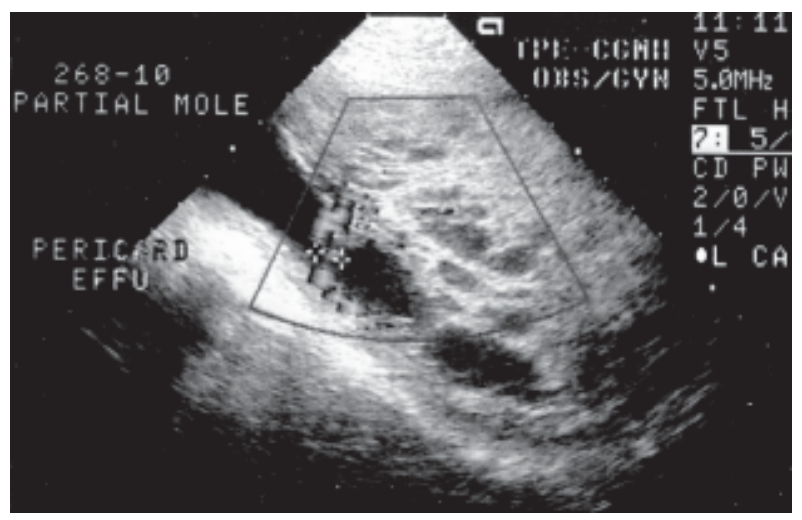

Fig. 1: Ultrasonogram of the uterus at $23^{\text {rd }}$ week of pregnancy

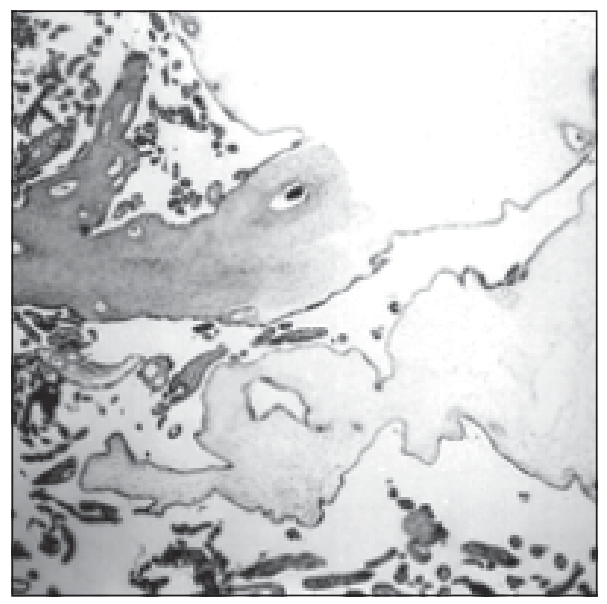

Fig.-2: Microscopic picture of the placenta showing an admixture of normal villi and molar villi with dilated cistern formation (Histopathology Laboratory, BIRDEM Hospital, Dhaka).

\section{Discussion:}

Hydatidiform mole with coexistent normal foetus is not necessarily considered as a partial mole. Cases of such association can be classified into three types. The first is a twin pregnancy with one normal foetus (normal placenta) and another complete mole $\mathrm{e}^{9-11}$; the second is a twin pregnancy with one normal foetus (normal placenta) and another partial mole ${ }^{12,13}$, and the third is a singleton normal foetus with partial molar placenta ${ }^{3,4,6,9}$ as in our patient. In cases of a singleton normal foetus with partial molar placenta, the foetus must have normal karyotype to survive in utero, although its placenta can have some variation, from diploidy of the amnion to triploidy of the chorionic villi ${ }^{6}$. From this clinical perspective, there are two different types of gross pathology in the placenta: the focal and diffuse partial degeneration ${ }^{3,7,14}$. The difference between a focal partial molar degeneration and twin pregnancy with complete mole cannot be firmly established by ultrasound. Because they both present with two distinct regions of the placenta. On the contrary, ultrasonographic detection of diffuse partial degeneration is much easier because of the readily identifiable characteristic picture as in the case of our patient. Our prenatal diagnosis of diffuse partial mole depended upon the ultrasonographic finding of molar invasion into the normal placenta without clear margin. The prognosis is grave because of the relatively smaller region of functional placenta. Only one case of diffuse partial molar pregnancy in which the infant survived has been reported ${ }^{6}$. Most of the cases of partial molar pregnancy diagnosed early in the gestation have been terminated $^{10}$ with or without medical complications. Partial molar pregnancy with fetal survival depends upon several factors: (i) normal karyotype of the foetus ${ }^{6}$, (ii) smaller molar placenta compared to normal placenta ${ }^{3,7}$, (iii) the onset of the molar degeneration and its speed of degeneration ${ }^{3,6}$, (iv) absence of anaemia occurring in the foetust; and (v) absence of maternal complications such as preeclampsia, thyrotoxicosis, and vaginal bleeding interrupting the pregnancy ${ }^{5}$. The distinction between normal and abnormal placenta on ultrasound might occur in either partial mole with focal degeneration or twin pregnancy with one foetus and another partial or complete mole ${ }^{7,11}$. The coexistence of a partial mole with a normal live foetus is rare. The present case was followed sonographically from the $23^{\text {rd }}$ gestational week until birth. Ultrasonographic examinations before delivery found no signs of congestive heart failure such as foetal ascites, pleural effusion or skin 
oedema nor any other evidence of chronic fetal blood loss throughout the pregnancy. Our patient did not show any persistent trophoblastic disease after birth and her serum $\alpha$-HCG titre returned to normal within 4 weeks. Termination of the partial molar pregnancy is sometimes necessary because of preeclampsia $(2.5-6 \%$ of cases) or heavy vaginal bleeding $(8 \% \text { of cases })^{14,15}$. Although the partial mole displays most of the pathological and clinical features of the complete mole, it seems to represent a milder version of the latter, as seen in placental morphology $\alpha$ HCG titres, and the incidence of preeclampsia, thyrotoxicosis, hyperemesis, and haemorrhage. For this reason, we do not think it is necessary to terminate partial molar pregnancy, when the foetus was normal and there were no clinical complications.

\section{Conclusion:}

In conclusion, pregnancy with a normal live foetus and a partial molar placenta is extremely rare because of maternal and fetal complications. These complications include preeclampsia, hyperthyroidism, heavy vaginal bleeding, persistent gestational trophoblastic disease, preterm labour, and late abortion.

\section{References:}

1. Ohama K, Ueda K, Okamoto E, et al. Cytogenetic and clinicopathological studies of partial moles. J Obstet Gynecol. 1986, 68: 259-66.

2. Szulman AE, Surti, U. The syndrome of hydatidiform mole. I.Cytogenetic and morphologic correlations. Am J Obstet Gynecol. 1978; 131: 665-71.

3. Jones WB, Lauersen, NH. Hydatidiform mole with coexistent foetus. Am J Obstet Gynecol. 1975; 122, 267-72.

4. Crooij MJ, Harten VD, Puyenbroek JI, et al. A partial hydatidiform mole, dispersed throughout the placenta, coexisting with a normal living foetus. Case report. Br J Obstet Gynaecol. 1985; 92: 104-6.

5. Teng NNH, Ballon, SC. Partial hydatidiform mole with diploidy karyotype: report of three cases. Am J Obstet Gynecol. 1984, 150: 961-4.

6. Sarno AP, Moorman AJ, Kalousek DK. Partial pregnancy with fetal survival: an unusual example of confined placental mosaicism. J Obstet Gynecol. 1993, 82: 716-9.

7. Deaton JL, Hoffman JS, Saal H, et al. Molar pregnancy coexisting with a normal foetus: a case report. Gynecol Oncol.1989; 32: 394-7.

8. Feinberg RF, Lockwood CJ, Salafia C, et al. Sonographic diagnosis of a pregnancy with diffuse hydatidiform mole and coexistent $46, \mathrm{XX}$ foetus: a case report. Obstet. Gynecol. 1988, 72, 485-8.

9. Sauerbrei EE, Salem S, Fayle B. Coexistent hydatidiform mole and live foetus in the second trimester. Radiology. 1980; 135: 415-7.

10. Changchien CC, Eng HL, Chen WJ. Twin pregnancy with hydatidiform mole $(46, \mathrm{XX})$ and a coexistent foetus $(46, \mathrm{XY})$ : report of a case. $\mathrm{J}$ Formos Med Assoc.1994; 93: 337-9.

11. Chen, F.P. Molar pregnancy and living normal foetus coexisting until term: prenatal biochemical and sonographic diagnosis. Hum Reprod.1997; 12: 442-4.

12. Nwosu EC, Ferriman E, McCormack MJ, et al. Partial hydatidiform mole and hypertension associated with a live foetus-variable presentation in two cases. Hum Reprod.1995; 10: 2459-62.

13. Nugent CE, Punch MR, Barr M, et al. Persistence of partial molar placenta and severe preeclampsia after selective termination in a twin pregnancy. Obstet Gynecol. 1996; 87: 829-31.

14. Vejerslev LO. Clinical management and diagnostic possibilities in hydatidiform mole with coexistent foetus. Obstet Gynecol Surv. 1991; 46: 577-88.

15. Berkowitz RS, Goldstein DP, Bernstein MR. Natural history of partial molar pregnancy. J Obstet Gynecol. 1985; 66: 677-81. 